\title{
Humor: A pedagogical tool to promote learning
}

\author{
M Chabeli, PhD \\ Department of Nursing, University of Johannesburg
}

Key words: Humor, Learning, Pedagogy

\section{Abstract: Curationis 31(3): 51-59}

Background: It has become critical that learners are exposed to varied methods of teaching and assessment that will promote critical thinking of learners. Humor creates a relaxed atmosphere where learning can be enhanced and appreciated. When learners are relaxed, thinking becomes eminent. Authoritative and tense environment hinders thinking.

Aim: This paper seeks to explore the perceptions of nurse teacher learners regarding the use of humor as a pedagogical tool to promote learning.

Method: A qualitative, exploratory, descriptive and contextual research design was employed (Burns \& Grove, 2001:61; Mouton, 1996:103). 130 naïve sketches were collected from nurse teacher learners who volunteered to take part in the study (Giorgi in_Omery, 1983:52) Follow up interviews were conducted to verify the findings. A qualitative, open-coding method of content analysis was done Tesch (in Creswell, 1994:155). Measures to ensure trustworthiness of the study were taken in accordance with the protocol of (Lincoln \& Guba, 1985:290-326).

Implications for nursing education, training and practice: The findings of the study will assist the nurse educators to create a positive, affective, psychological and social learning environment through the use of humor in a positive manner. Nurse educators will appreciate the fact that integration of humor to the learning content will promote the learners' critical thinking and emotional intelligence. Negative humor has a negative impact on learning. Learner nurses who become critical thinkers will be able to be analytical and solve problems amicably in practice.

\section{Introduction}

There is a continuous debate and dialogue about how teaching and learning can be facilitated. Teachers are urged to seek better and alternative ways of teaching to improve their practice over and above the use of the traditional methods of teaching. It is not often acknowledged that one can effectively use oneself to improve one's teaching and learning practice. How the teacher undertakes the teaching role in class, the teacher's disposition, and the positive use of humor, will instill confidence and respect to the teacher and will create a trusting relationship between the teacher and the learner. A helping attitude, openness, willingness and an empathetic disposition on the part of the teacher will determine the degree to which the learner will believe in the teacher, and therefore take responsibility for his or her own learning.

A teacher who creates an environment conducive to teaching and learning through positive, goal-directed humor will make the learner gain confidence and be eager to learn more because a truly concerned, committed, understanding, knowledgeable, high-spirited and supportive teacher is there to aid learners in regaining control of their own learning. The use of humor to enhance teaching and learning demonstrate passion on the part of the teacher and shows that he or she does not see teaching simply as a chore that must be done. Humor used as a pedagogical tool also helps the teacher 
to maintain a lively and engaged relationship with the learner. The teacher regards learners as unique human beings whose learning needs are to be met and not as objects who must be fed with book knowledge in a tense atmosphere.

Kelly (2005:5) argues that the teacher's main job is to help students fall in love with the content and their own learning. Teachers have the most influence and power on the learners. They can mould an appreciation for the subject, depending on the approach. They can create a learning environment filled with hope, trust, respect, interest, positive attitudes, creativity, unpredictability and fun through the use of humor. All these aspects enhance the learning process and motivate and energize both the teacher and the learners. Teachers are urged to make humor an integral part of the curriculum rather than using it only after completing serious work (Kelly, 2005:4). Humor used as a pedagogical tool can be very effective in motivating students to engage with the subject matter. According to Robinson (in Hayden-Miles, 2002:1), humor provides a caring environment within which criticism and values can be expressed and mistakes pointed out without destroying the learners' self-image. Humor is embedded in a particular social environment.

It is crucial and challenging for teachers to draw on the learning experiences of learners for continuous teacher development. This is achieved by sharing their unique educational stories and constantly reflecting on their teaching practice. Teachers should realize the power of using the learners' previous knowledge, skills and attitudes to create space for learners to deconstruct and construct their own knowledge. Human collaboration and dialogue is in the forefront in facilitating teaching and learning. Teachers should realize the power of learning from what learners tell them. Teachers should become colearners in the process of teaching and learning hence this article is focused on exploring the perceptions of nurse teacher learners regarding the use of humor as a pedagogical tool to facilitate learning.

\section{Problem statement}

Although some researchers have studied the use of humor in nursing education, the strategy is not seen as an effective

Table 1: Perceptions of nursing education learners regarding the use of humor as a pedagogical tool to facilitate learning

\begin{tabular}{|l|l|}
\hline POSITIVE HUMOR & NEGATIVEHUMOR \\
\hline $\begin{array}{l}\text { 1. Promote learning through. } \\
\text { Creating a positive, affective, } \\
\text { psycho-social learning } \\
\text { environment }\end{array}$ & 1. Impacts negatively on learning \\
$\begin{array}{l}\text { 2. Promote critical thinking } \\
\text { 3. Promote emotional intelligence }\end{array}$ & \\
\hline
\end{tabular}

pedagogical

tool to facilitate learning as is cvidenced by the lack of its application - particularly in clinical nursing education where anxiety and tension prevail (Ulloth, 2003:127). The following research questions emanate from the introduction: what are the perceptions of nursing education learners regarding the use of humor as a pedagogical tool to facilitate learning? What guidelines can be formulated to improve learning through the use of humor?

\section{Aim}

The study seeks to explore the perceptions of nursing education learners regarding the use of humor as a pedagogical tool to facilitate learning and to formulate guidelines to improve teaching and learning through humor.

\section{Definitions of key concepts}

In this study both the conceptual and operational definitions will be defined. A conceptual definition conveys the research's perspective on the concept humor. This definition is not sufficient in itself because it does not specify how humor is to be observed and / or measured, that is, the specific steps the researcher must take in order to gather the required information which is the function of operational definition (Brink, 2001:95).

\section{Humor}

Humor is conceptually defined as an attitude, a perspective, a set of skills that can help a person to achieve important goals in life. Humor certainly includes jokes, but it goes way beyond joke-telling (Goodman, 2005:6).

\section{Positive humor}

In this study, the operational definition of positive humor refers to an attitude or perspective

that will reduce the tension in class. Learners feel relaxed, open and accepted. The atmosphere is more sociable and learners can converse or answer questions in class more freely without feeling intimidated by the teacher. The teacher who makes use of humor positively to promote learning will be more approachable and appealing to learners. Learners experience learning with enjoyment and thus thinking and creativity takes place more readily (Goodman, 2005:5)

\section{Negative humor}

On the other hand, negative humor is operationally defined as an attitude or perspective that is intended to belittle, ridicule, discriminate and encourage negativity amongst learners. Negative humor is disruptive and can divide learners (Kelly, 2005:2).

\section{Learning}

Learning is an activity in which the person being taught actively wishes to benefit from the teaching and engages with a particular learning content for the purpose of understanding it and understanding how it can be used in practice (Fraser; Loubser \& Van Rooy, 1993:3).

\section{Learner}

A learner is conceptually defined as an individual who obtains knowledge and skills from the learning content under the supervision and guidance of the teacher and becomes increasingly competent in obtaining, interpreting and using knowledge and skills in an independent manner. The learner has to learn in a formal, structured and disciplined way (Fraser et al, 1993:8, 15).

In this study learners are registered nurses who are undertaking a post-basic 
degree course on a regular one day per week at a university in Gauteng. The course is approved in terms of section 15 (2) of the Nursing Act (Act 50 of 1978 as amended) directed by Regulation 118 of 1987 with the aim of registering the learner on completion with the South African Nursing Council for additional qualification in nursing education.

\section{Pedagogics}

Pedagogics refers to the science which studies education as an aspect of reality, that is, teaching and learning and all its related aspects (Fraser et al., 1993:5). In this study, the science referred to studies the educational activity as it occurs between adults.

\section{Research design and method}

An exploratory, descriptive and contextual qualitative research design was employed to gain insight through exploring the depth, richness, and complexity of the data inherent in humor used as a pedagogical tool to facilitate learning (Burns \& Grove, 2001:61; Mouton, 1996:103). The aim of exploratory studies is to establish facts, to gather new data and to determine whether there are interesting patterns in the data (Mouton, 1996:103).

\section{Data collection method}

The perceptions of nursing education learners concerning the use of humor as a didactic tool to facilitate learning were gathered through descriptive naïve sketches Giorgi (in Omery, 1983:52) followed by individual interviews to verify the findings. Burns and Grove (2001:102) assert that descriptive or factual knowledge which includes data, facts, narratives and stories provide truthful descriptions of the phenomenon under study. The nature of descriptive naïve sketches is inductive, exploratory and descriptive in order to investigate and describe all phenomena, including the human experiences in the way these phenomena appear "in their fullest breath and depth". The researcher approached the study with no preconceived expectations or categories. That is, the subject to be studied was approached naively, all data was understood from the perspective of the participants and was accepted as given (Giorgi in Omery, 1983:50).

From a class of 150 final-year students for a post-basic degree in nursing, a purposive sample of 130 students volunteered to participate in the study. The other 20 students did not attend class on the day the data was collected. The study took place at the end of the second semester. Research questions were written on a transparency for students using an overhead projector as follows:

1. What are your perceptions regarding the use of humor as a pedagogical tool to facilitate learning?

2. What guidelines can be formulated to facilitate learning through the use of -humor?

Students were given enough sheets of paper to write on. Participation was strictly voluntary and they signed a consent form. No disturbance was envisaged as the venue was far from telephones. Participants were assured confidentiality in the sense that only the researcher and the co-coder would be in a position to read the responses during data analysis. They were ensured that sheets would be destroyed after the study was completed. Anonymity was ensured in that they were given instructions not to write their names on the sheets. They were told that they could withdraw their participation at any time they wished to without threats of prejudice from the researcher. Participants were allowed to write without any time limit so that perceived ideas and thoughts on the research topic could unfold as they existed. As participants were writing, the researcher was collecting field notes to demonstrate the participants' individual dynamics and gestures to enrich and support the collected data (Lincoln \& Guba, 1985:272). In fifty minutes, all participants had completed the naïve sketches and most of them were laughing as they handed them in.

\section{Data analysis}

Tesch (in Creswell, 1994:155)'s qualitative open-coding method of data analysis was used. The researcher slowly read the entire descriptions to get the sense of the whole and to identify individual units. Redundant information was eliminated and the meanings of the remaining units were clarified by relating them to each other and to the whole. Data analysis proceeded inductively by classifying common descriptions into themes. An external coder, who is familiar with the data analysis protocol, was purposively selected to independently analyze the data according to Tesch (in Creswell, 1994:155)'s data analysis protocol. A consensus discussion meeting between the researcher and the co-coder was held to arrive at a common understanding about the identified themes.

To acquire in-depth information and to verify the common themes about the perceptions, a follow up interview was conducted with 20 participants from the previous sample who also volunteered to be interviewed for the purpose of verifying the themes. Verification is a process of improving efficiency and quality that can ultimately lead to quality products. It is literally about verifying and confirming the validity of a phenomenon. It should be understood as a driving force of quality which compels us to seek improvement (Murphy, 1995:15).

\section{Trustworthiness}

The four principles to ensure trustworthiness of the study were used, that is credibility, transferability, dependability and conformability (Lincoln \& Guba, 1985:290-326).

\section{Credibility}

The following measures increased the credibility of the study: the researcher's extensive knowledge of qualitative research paradigm and the engagement of an external co-coder in data analysis process. The co-coder is an expert in qualitative research strategy qualified in nursing education. Triangulation of sources was attained by using various credible primary and secondary sources on the use of humor in teaching and learning.

An existing protocol for qualitative opencoding data analysis was used Tesch (in Creswell, 1994:155). Findings were recontextualized for the purpose of formulating the guidelines to facilitate learning through humor. The findings from naïve sketches were verified through conducting follow up interviews in an attempt to increase the credibility of the study. Structural coherence was maintained by consistently asking about the perceptions regarding the use of humor as a pedagogical tool to facilitate learning. 


\section{Transferability}

Although the study is contextual in nature, the need to improve teaching and learning is a universal one to all educators, in particular, in clinical nursing education where there is continuous tension. The author assumes that the guidelines formulated will be of assistance to other nurse educators in improving learning through humor. The dense description of the method used for the study will make replication of the study by other researchers possible.

\section{Dependability and conformability}

The study was consistent across the qualitative methods of research, congruent with and guided by the research question (dependability audit). The use of external independent coder to reach consensus agreement on the categories and themes and the triangulation of sources increased the dependability and conformability of the study.

\section{Description and discussion of results}

The results of the study are described in accordance with Table 1. The participants perceived the effects of positive humor and that of negative humor as major categories. The positive humor category has its related themes as indicated in the table below. The results are conceptualized from literature and guidelines will be described to facilitate learning through the use of humor.

\section{Positive humour}

All participants indicated that humor, if used positively, promotes learning. Focus was put on humor as a means to create a positive psycho-social learning environment, and the effect of humor on the learner.

\section{Humor promotes learning through creating a positive, affective, psycho- social learning environment}

Humor is context-driven. Participants stated that "humor creates a relaxed atmosphere where dialogue can be enhanced. Humor neutralizes serious situations; a person feels open and accepted by the group. Humor makes the atmosphere more sociable and can be used as an ice-breaker as learners learn to know one another better. It reduces tension in class. Absenteeism is not experienced where humor is integrated to the teaching content. You want to be in class and enjoy. Humor makes learners to feel at home. Learners feel relaxed and can converse freely without being intimidated or threatened". Goodman (2005:5) is of the opinion that humor is a powerful exciting tool that diffuses anxiety and can also serve as a vehicle for change.

Participants felt that "the more laughing, the smaller the distance betw'een the learners and the teacher. The teacher who infuses humor into a presentation appears more approachable and appealing to learners. Learners can freely ask questions at any time". Furthermore, participants indicated "humor is a spice of my learning for it enables group engagement, sharing jokes, laughter and giggles which encourage group cohesion". Providing laughter and play for learners is important because it helps learners to think creatively, stretch their limitations and enable them to experience learning with enjoyment (Kelly, 2005:2). Brandt (2003:35) comments that during training, he uses humor since he feels that when people can laugh, they can feel comfortable, and comfort leads to confidence, which leads to competence. For Brandt, humor helps relieve the tension in a learning environment. Again, participants stated "we must be willing to risk in order to grow: If an attempt to use humor is genuine, the risk of failing is minimal". Humor gives learners a breather that allows them to regain their strength and pull their resources together. It is an important coping tool. It gives learners power and a new perspective. Humor makes learners look confident, assertive and objective. It provides an alternative view, gives new insight and possible solutions to problems (Kelly, 2005:3).

When learners feel at ease, secure and happy, they learn without fear, struggle or self-deception. Participants were of the opinion that if humor is used in a positive manner, it can make learners feel accepted and feel less serious about their imperfections. They stated that humor has the power to turn any situation around. Phillis Diller (in Kelly 2005:6) asserts that laughter is the universal language and a smile is a curve that sets everything straight. A smile is a light to tell people that your heart is at home. A teacher who is liked by learners will find that his or her teaching is better received than that of a hated teacher as cited: "it is difficult to trust the teaching of someone you do not like no matter how knowledgeable that teacher can be. If your learners like you, you will gain their admiration, respect, confidentiality and trust". Kelly (2005:6) is of the opinion that a smile is an instant communicator and a motivator and that is what teaching and learning are all about.

Participants believe that, to be able to use humor, you must have a sense of humor yourself. This is a fundamental aspect which teachers should address. This means that teachers must think about their own teaching practice, model humor as a didactic tool to facilitate learning and be creative in using specific teaching strategies that encourage learners to view humor as an enabling didactic tool to facilitate learning. The creative use of humor creates a unique bridge between cognitive and affective domains. The affective elements of humor such as openness, free to ask question or to discuss, passion of the subject etcetera, are integral to the holistic framework of nursing education and to nursing as a whole (Ferguson \& Campinha-Bacote, 1989:30). Teachers need to set aside time to develop and infuse humor into their teaching practice for the benefit of leamers and, ultimately, future nursing practice.

Humor enhances reflection. Scanlan and Chernomas (1997: 1142) contend that teachers cannot engage in reflective relationships with learners unless they give up their position as authoritative knowers. This opinion is reiterated by Caine and Caine (1994:144) who assert that teachers must never display a superior 'I-have-all-the-knowledge-onlease' attitude. Teachers should realize the power of building a trusting relationship and of maintaining a humorous, cooperative learning climate (Gravett, 2001:43). To many teachers, this shift is a challenge that can be addressed by the use of humor. If we expect learners to comfort patients with humor, we would do well to instill this ideal in our teaching practice. Teachers need to do introspection of their inner self, revisit 
their teaching styles and aim at building a collaborative relationship where learners and teachers interact harmoniously to discover the experiences of the learning situation together. Teachers should not lose sight of the fact that they are facilitators, guiders, mediators of learning and co-lcarners (Gravell, 2001:36, 37, 38). Through the use of humor. learning becomes a cooperative venture and both the teacher and the learner become jointly responsible for a process in which they all grow.

Learners remember facts that are linked to jocular examples. Humor reminds lcarners that they are all social, human beings as cited by participants: "if we can laugh together. we can learn together: dialogue together: cooperate and collaborate to facilitate effective learning". Humor strengthens social relationships among learners and teachers (Ulloth, 2(003:127, 128). It reduces the authoritarian position of the teacher, allowing the teacher to be a facilitator and a mediator of the learning process in partnership with the learner. By reducing anxicty, learners are more likely to focus their attention, experience learning as fun, and increase learning and memory. Learners open their minds to learning and enjoy the learning experience. I lowever, participants felt that humor should not be a substitute for poor teaching: "Mrs $X$ had us langhing throughout all her lectures without meaningful conncetion to the content. je' in the lest and examination she asks serious matrer: That is not good enough for learning to rake place". Atherton (2003:1) contends that humor is an important spice to use in teaching but like any spice, you don't want too much of it. Frequently, jokes are remembered readily, and so teachers find their jokes being solemnly repeated back to them in assignments and in cxaminations.

\section{Humor promote critical thinking}

According to the American Philosophical Association (APA) study directed by Facione (1900:2), critical thinking is understood to be self-regulatory judgment which results in interpretation, analysis, evaluation, inference as well as explanation of the evidential, conceptual, methodological, criteriological or contextual considerations upon which that judgment is based. It is csisentially a lool of onc's personal and civic life. indicated that the ideal eritical thinker is habitually inquisitive, well-informed. Irustful of reason, open-minded, llexible, fair-minded in evaluation, honest in facing personal biases, prudent in making judgments. willing to reconsider, clear about issues, orderly in complex matters, diligent in secking relevant information, reasonable in the selection of criteria, focused on inquiry, and persistent in sceking results which are as precise as the subject and the circumstances of inquiry permit. The American Philosophical Association combines developing critical thinking skills with nurturing the related affective dispositions, and this consistently yields useful insights, which are the basis of a national, democratic socicty.

The definition and the ideal critical thinking characteristies described above cannol be facilitated in a tense atmosphere. To educate learners to become critical thinkers requires the creation of the environment that is relaxed, enjoyable, non-judgmental, nonthreatening and non-intimidaling - yet stimulating, challenging and salc (Ciravell 2001:46), wilh a rich sensory environment that engages all levels of the mind (Caine \& Caine in Ulloth, 2003:127). The environment should be inviting and motivating. Participants stated the following observations: "in a straight-faced classroom there is no learning. There is less interaction of learners. There is fear and intimidation. One is not sure whether by asking a question you shall have caused trouble, worse if you can crack a joke. I carners spent most of their time studying the intimidating attitude of the teacher and they ask questions such as: who is she going to ridicule today? who is she going to belittle, humiliate or reduce in dignily or integrity? lixactly when is the class ending? When is one going to be freed from the monster teacher"'? These remarks raise a scrious concern for teachers: how do learners perceive you and your practice?

According to MePeck (1981:5) critical thinking always manifests itself in connection with identifiable activity or subject area and never in isolation. McPeck (1981:3) further state that to critical thinking is always thinking about somcthing since, to think about nothing is a conceptual impossibility. ('ritical is logically entailed in education and it can improve education. MePeck (1981:37) argue that critical thinking must command a place in any institution committed lo the pursuit of education because critical thinking is a necessary condition of it. However, for critical thinking lo lake place, a relaxed. stimulated enviromment is mandatory and the use of humor positively can make this ideal possible.

A learning climate to facilitate critical thinking involves the stimulation of both the cognitive and the aftective components in a domain-specilic context. The two components cannol be separated. Learning is both a rallional and an affective endeavor. During the learning proeess, the reasoning and emotions of the learners are involved. Using humor that is appreciated by learners can act as intrinsic motivator because it will elicil positive emotion. while generating sustained interest and involvement in the construction of onces own karning (Wlodkowski, l998:96-1(0)). $\Lambda$ positive use of humor can challenge learners to engage in problem- solving activities, the resolution of contradictions, and the justilication of their views. They will also want to know the different alternatives to the solution of the problem. Teachers need to create a salc, challenging learning environment in which learners lect liee to explore, experiment, make mistakes through trial and error, ask challenging questions freely in a state of "relaxed alertness" (Cainc \& (ainc in (iravell, 200)1:46)

$\Lambda$ relaxed mental alertness will encourage challenging interactions. It will invite dialoguc and provide both the leacher and the learner with the opportunity to critically analyze, interpre, synthesize, make inferences, explain and evaluale assumplions, belicts, thoughts and actions. This shoukd include interactions where learners are confronted with opposing and alternative views to trigger cognilive disequilibrium. Cognitive disequilibrium is the tension people fect when they experience something lhat does not fit what they already know. This tension causes them to involve themselves with the new experience until they can understand or fil into what lhey know or can do (Wlodkowski, I998: 107). (n the other hand, Woolfolk (I)90:46) explains discyuilibrium as disturbance in scarch of mental balance. I iscequilibrium caltses learners lo be uncom fortable and this motivates them to keep on searching for a solution. Thus critical thinking is 
stimulated and learning takes place.

Using humor in a challenging manner within the appropriate learning context, or designing humor around the educational point being made, will induce learners to think and rethink their understanding of the content and examine their reasoning so that new knowledge can be constructed (Powell \& Andresen in Ulloth, 2003:127). The appropriate use of positive humor will provide the climate in which learners feel encouraged to express their views and to oppose those of others without experiencing the situation as threatening. Learners gain self-confidence and freely take part actively from the onset and demonstrate respect and passion for the subject once they realize that their contributions are appreciated (Hammond \& Collins, 1991:48).

The dynamic that underpins critical thinking is the interactive, collaborative participation of learners using dialogue in a relaxed atmosphere (Gravett, 2001:41). This dynamic will not be made possible in a rigid, authoritarian environment. The participants noted: "humor encourages a healthy participation by all learners regardless of race or religion. With humor; complex mental activities such as critical thinking, decision-making and problem-solving can be easily accomplished, because humor invites discussion and dialogue. Through dialogue we can analyze, interpret, explain and evaluate issues according to our understanding. We can actively, listen to the view's of other learners, synthesize them and come up with different and new insights or perspectives. For those who are slow in grasping, we can explain to them at our ou'n pace, evaluate and monitor our understanding without fear of intimidation".

Humor creates the climate for inquisitiveness. Learners want to go beyond 'book knowledge' because, according to participants, the teacher is open-minded, flexible and approachable. Probing questions are used without fear of intimidation. The skills of inferencemaking and evaluation of issues are easily developed where humor is infused into the content. In a humorous climate it is easy to concentrate. Learners remember better when a humorous image is used to explain a phenomenon. The learners' selfconfidence is boosted. They are encouraged to come to class where humor is used as a pedagogical tool. There is a feeling of belonging to the group with a positive attitude to each other as cited: "we feel awake, motivated, inspired, stimulated and empowered. It breaks the silence and rigidity: We feel open and accepted. We have an open-minded approach to our learning." Learners further felt that through humor, they are able to create a respecting and trusting relationship with other learners and lecturers. The teacher perceives learners as unique individuals with an inherent right to learn. "We want to enjoy the presentation so as to look forward to attending the next lecture" participants remarked.

Through humor the teacher's characteristics come to the fore. The motivation, approachability, the enthusiasm, the passion for own subject, the expert knowledge and experience will be displayed by the ability to infuse humor into the content, by formulating examples using humor so that learners remember more readily - i.e. relating the learner's preconceptions to the knowledge. Humor increases the teacher's coaching, facilitating and guiding abilities. It increases the teacher's critical and reflective abilities.

Teachers who have a sense of humor are usually accepted by learners because of their good, less authoritarian attitude. Respectful and trusting relationships are also built between the learners and the teachers. Learners become more receptive to the learning content. "Humor is like medicine for the soul and heals whatever emotional scars we might bring to class. Things learned in a humanistic way are better remembered. Humor helps the teacher to go down to the learners and reduces the distance between the learner and the welllearned person. If learners enjoy the class, they will enjoy the subject and strive to do well. It keeps the learners' attention. Humor makes us to appreciate ourselves and teachers even more", said participants.

Critical thinking is promoted through dialogue. According to Gravett (2001:36), meaningful dialogue that intends to break through to new insights and is marked by an attitude of reciprocity among learners underpinned by interest, trust, respect, and sharing of this educational journey can only take place in a relaxed atmosphere and the use of humor plays an integral part in creating such an atmosphere. The word dialogue derives its meaning from the Greek words 'dia' which means 'two', a connection between, across or through, and 'logos' which denotes thought, reason, meaning and judgment. Dialogue is summarized by Burbules (in Gravett 2001:35) as a form of social relations that engages participants. A successful dialogue involves an exchange of perspectives, experiences and beliefs in which participants engage in willing partnership and co-operation in the face of likely disagreements, confusion, failures and misunderstandings. Persisting in this process requires a relaxed environment characterized by an attitude of mutual respect, trust, openness, active listening and concern. Use of humor encourages dialogue as an authentic learning process during which meaning is consistently gathered and unfolded in the process of attaining understanding. This learning process takes place in an explorative manner. Dialogic teaching integrated with humor implies that the educator, the learner and knowledge should be engaged in a dynamic reciprocal unity (Gravett \& Henning 1998:61).

\section{Humor promote emotional intelligence}

Emotional intelligence can be conceived as a measure of the degree to which a person successfully (or unsuccessfully) applies sound judgment and reasoning to situations in the process of determining an emotional or feeling response to those situations. It would entail the bringing of cognitive intelligence to bear upon both positive and negative emotions. It would be a measure of the extent to which our affective response was 'rationally' based. Goleman (1998:317) defines the term 'emotional intelligence' as the capacity for recognizing our own feelings and those of others, for motivating ourselves, and for managing emotions well in our relationships. Emerging naturally out of rational emotions would be reasonable desires and sensible behavior.

To maintaining positive emotions while learning enlightens one's emotions and sustains interest and involvement in the learning activities. The appropriate use of humor can also contribute to the development of emotional intelligence' as it creates a relaxed atmosphere where learners feel safe, capable and accepted. 
Leamers realize that they are also allowed to err. Laughter can go a long way in improving a tense atmosphere and in reenergizing learners, particularly when the learning content is complex, controversial or intimidating, especially in a clinical learning situation. Humor can help pacify emotions and relax learners. Humor appropriately integrated with content and making use of the learners' previous knowledge, can serve as a 'hook' for remembering important content (Apps in Gravett, 2001:44, 45). Both the mind and the heart must be involved for effective learning and teaching to take place (Freshwaters \& Stickley, 2004:91 98).

The concept emotional intelligence has become a buzzword in the field of education. Teachers who are able to demonstrate emotionally intelligent behavior in the classroom have been known to be more effective in achieving the academic goals they have set for themselves and their learners. Demonstrating emotionally intelligent behavior helps create an emotional climate which enhances learning, reduces peer conflicts and creates a more desirable teaching situation (Cobb \& Mayer, 2000:58;17).

Emotional intelligence provides the skill to control and to manage the emotions successfully. The concept of emotional intelligence implies that people are both rational and emotional beings. Adapting and coping abilities in a social context depend on the integrative functioning of rational (cognitive) and emotional (affective) capacities (Fineman 2000: 101). It is through reasoning that individuals identify what emotions they are experiencing, discover the beliefs and values that give rise to them, and decide what actions, if any, to take on the face of it (Locke 2005:425-431; Thingujam 2004:155-166).

Emotional intelligence emphasizes the cognitive, affective and social aspects of behavior The cognitive aspect of emotionally intelligent behavior relates to the intelligent reasoning about the emotions one is experiencing and includes skills such as emotional awareness, self-control and assertiveness. The affective aspect of emotionally intelligent behavior refers to the ability to harness one's emotions and mood as a source of energy to positively influence one's wellbeing, goals, plans, survival and social role performance. It also includes personality aspects such as general mood, optimism and happiness (Cooper \& Sawart, 2000:324).

The social aspect of emotionally intelligent behavior relates to individuals' personal effectiveness in interpersonal interactions. It includes the ability to notice and make distinctions between other individuals, their moods, temperaments, motivations and intentions and to use this information to regulate and guide one's thinking and actions in achieving one's goals in a socially acceptable manner. It includes skills such as empathy, respect, flexibility and unconditional acceptance of others (Cooper \& Sawart, 2000:324).

The following quotations from the participants characterize the teacher who has emotional intelligence, that is, who is emotionally balanced: "the teacher always smiles, keeps her voice low, does not shout, she is always polite. Treats us friendly, is assertive, firm and strict. Creates a professional distance between $\mathrm{him} / \mathrm{her}$ and the learners, speaks gently with a happy face, guides learners properly, his/her enthusiasm lifts our spirit. Demonstrates passion and devotion to teaching learners, is very energetic, has a positive attitude, is patient in listening to our problems and takes individuality of learners into consideration".

Humor is a risky business because the teacher does not always know the learners' personalities and experiences so there is always some risk involved when jokes are used. Teachers need to find out about the background of learners first, by assessing their religious and cultural background and establishing some rapport with them. Kelly (2005:2) is of the opinion that humor has so much force that it can communicate and connect or easily separate and destroy relationships. Humor can educate or denigrate, heal or harm, embrace or deface situations

\section{Negative humor \\ Impacts negatively on learning}

There are primarily two types of humor: appropriate and inappropriate. Any humor that is intended to divide people, belittle or ridicule, discriminate, encourage negativity or be at another person expense is inappropriate.
According to Kelly (2005:2), inappropriate humor offends people and comes from a closed heart. Inappropriate humor is disruptive and should be handled in the same manner as any type of disruptive behavior, move quickly to change the subject and gain control. Negative humor can have adverse impact on learning. Participants indicated: "humor should not be excessive such that the teacher becomes off focus from the learning outcomes and hurts learners. Humor must be used to emphasize or clarify a point. It would be ideal to use it as an introduction, for example, explanation of complex issues and for closure of the lecture. Humor should not be used to degrade or mock the learners' efforts. Hurtful humor or jokes can turn a possible positive learning event into a negative, resentful situation. Humor should be appropriate to the learning content and be applicable if the situation arrives". Negative humor is brutal and hostile, and self-esteem can be wounded (Torok, McMorris \& Wen-Chi Lin, 2004:19). Not all learners appreciate humor or have a good sense of humor. Teachers should be alert when using humor and should consider the presence of leamers from diverse racial cultural and religious backgrounds.

The negative use of humor is accompanied by feelings of frustration, anxiety, confusion, defensiveness and anger (Gravett, 2001:43). That is why some very intelligent learners who are achievers get themselves busy with constructive work like reading while the rest of the class is laughing. Such learners easily get bored and feel that humor is a waste of time - worse if it is negative and irritating. According to Klopper (2000/ $1: 90$ ), such learners are categorized as achievement-orientated learners who are highly structured and do not entertain jokes in class. Their time and work space is fully utilized and they concentrate on what counts, they avoids acts and jokes that waste time (Klopper, 2000/1:90). The aim of learners with such an approach to learning is to acquire book-related content, write tests and get distinctions. Such learners will be irritated by meaningless humor. The teacher will have to keep a balance and integrate humor and content to clarify complex issues. The participants stated: "too much humor can disrupt my concentration. Humor should not be used to hide or disguise the weakness of the tutor but rather to guide and encourage learners". 
Kelly (2005:7) believes that frequent belly laughter cures lerminal lightness, cerebral stiffiness and hardening of the attitudes and that -HI: II: I!' (latughing) olten leads to "Aha!" (indicates the acquisition of new insight and perspectives).

It is stricaly taboo and educationally unsound to use humor at the expense of the learners feclings or hy demcaning any person or group in a kearning situation. Respect and the integrity of each learner should be salted in ways that welcome lhe woth and expression of onc:s true self withoul lear of threalt. leamers should lied salfe capable and "relcomed. Ilumor should be used to enhance understanding and enlighlemment(cirarell. 20()1:40).

Nexaltive humor may not only have an impare to the learners diredly but may also allect their perceptions of the falculty member (Torok. MeNlorris \& Win-Chi Lin. Z(K) $2(0)$.

Learmets mention that humor has the power to make cachers more likeable. lacilitale understanding of courso material. lower tension. boost learners" morale, increase learners" atlentiveness and promote a sense of communicating From the description of the perceptions of participants and the related literature. the follow ing gudelines emerged.

\section{Guidelines to facilitate learning through the effective use of humor}

\section{- create a more positivi.}

altective, psicho-social and social learning ems iromment to promote leaming by breaking down batriers to communication between the leacher and kearners.

Adope a lighto plasful mindset to help establish a watm. sate larning enviromment.

l'se facial animation i.c. smile. make lucly expessions and let your eves sparkle. Adopt a latughing-ready attitude lsc comtortable bods language and a relaxed roice. message millches your rerbal messige. for example. humor used "Ith sorious body

language may be perecived as sarcasm by lamers.

Usc humor in a way that fecls natural and unique lo you: do not imitate the style used by oher teachers.

Reflect on what happened and why your humor was wellreceived. Consider how the same type of humor could be used in future.

- Develop your ability to read your learner tension levels.

- When you sense tension. Iry to defuse it by making a humorous rematk or lelling a funny story.

- Integrate humor to the content llumor does not halve to be a diversion from the curriculum. Whenere possible. "wave humor into what your leamers arc alleady learning.

Mleaningful humor should comnect new knowledge to previous leaming or experience

Tap your own imagination for innovative ways to bring the many benctits of humor to your learners" learning experiences.

Increase interpersonal contalet through eye-to-cye and face-toface contict (Provinc. 20(0):210214).

- Humor should be constructire. understandable by all learners and be relevant to the content and or compatible to the leaming env iromment.

Provide an engaged. relaxed atmosplace though humor.

Enjoy the leamers. the content and the process of teaching and learning (Toroket al.. 2004:21).

Recognize bad or destructive humbr. Sarcasm is dangerous and inappropriate in class and should be aroided at all costs as it 1 ill demorat lize students.

Make humor an integral part of vour class, rather than somethung special. The best hind of humor is "just-in time" humor - that is. a spontancous and comextual humor that arises naturally. Don t try too hard: encourage humor. don t force it. Do what tits vour persomality. It happens on its own. The learners are ready to leam effectively: volumarily ontask with minds that are open and relaxed

- Encourage learners to develop a group identity, to tocus on enjoving themselves while supporting each other. People love to laugh (Gravett. 2(0)1:H).

Learners should associate the curriculum with tiun and become committed to paying attention.

- However. enforec ground rules that keep the class profiessional and productive. but give learners plenty of lecway for intusing class activitics with spirited excitement. When they are excited they will learn faster and retain information more fully.

- The learners" humor should be driven by personal relationships set within the context of your curriculum. It should be relevant to the content.

- Be carcful not to over use humor. it could lose its value and effect. Develop a style and comfort zone with humor:

\section{Conclusion}

The effects of both positive and negative humor have been discussed. The guidelines to facilitate learning through the effective use of humor have also been described. It is for the teachers and learners to realize that humor can act as a lubricant or a retardant in the edtcattional setting. It caln educate or denigratte. heal or harm. embrace or detace (kelly. 2005:2). It is a pouctiol communication and pedagogical tool to be embraced by teachers and leamers. The use of humo is adrocated to facilitate learning and increase recall of the learning content. Furthemore. a humorous class activity relesant to the situation can serve as a book" for remembering important content (Apps in Gravett. 2001:44). Valla (in Gravelt. 2001:37) insist that whatever impedes dialoguc and humor must bo courageously addressed and eradicated and whaterer enables dialogue and humor must be fearlessly natured and usced.

Teachers are urged to be role models for some leamers maly adopt the teachers presentation style. Teachers should be enthusiastic and have passion in their subjects and this will be demonstrated by: the intelligent. ereative and meaning ful integration of humer into the 
content; be enthusiastic, that is, demonstrate intense and lively interest, passionate zeal, caring and feeling about your subject; strive to establish a cooperative learning climate interacting respectfully with leamers. Building of trust and respecting the individual learner's religious and cultural background is the mainstay of facilitating learning through humor.

\section{References}

ATHERTON, JS 2003: Learning and teaching through humor. http:// www.dmu.ac.uk/ jamesa/teaching/ humour.htm. (accessed 12 September 2006).

BRANDT, DS 2003: Training: Hey, what's so funny? Computers in libraries. Westport: September. 23 (8): 35-38.

BRINK, HI 2001: Fundamentals of research methodology for health care professionals. Cape Town: Juta \& Co, Ltd.

BURNS \& GROVE SK 2001: The practice of nursing research: conduct, critique and utilizations. Philadelphia : WB Saunders Company.

CAINE, RN \& CAINE, G 1994: Making connections: teaching and the human brain. Menlo Park: Addison-Wesley, CA.

COBB, CD \& MAYER, JD 2000: Emotional intelligence: What the research says. Emotional Leadership. 58 (3):14-18.

CRESWELL, JW 1994: Research design: qualitative and quantitative approach. London: Sage Publishers.

COOPER, RK \& SAWAF, A 2000: Executive EQ: Emotional intelligence in business. New York: Texere Publishing Limited.

FACIONE, PA 1990: Critical thinking: A statement of expert consensus for purpose of educational assessment and instruction. Executive summary "The Delphi Report”. Millbrae: California Academic Press.

FINEMAN, S 2000: Emotions in organizations. London: Sage.

FRASER, WJ; LOUBSER, CP \& VAN ROOY, MP 1993: Didactics for the undergraduate students. Durban:
Butterworth.

FRESHWATERS, D \& STICKLEY, T 2004: The heart of the art: emotional intelligence in nurse education. Nursing Inquirv, 11(2): 90-98.

FERGUSON, S \& CAMPINHABACOTE, J 1989: Humor in nursing. Journal of Psvchosocial Nursing and Mental Health Services. 27 (4): 29-34.

GOLEMAN, D 1998: Working with emotional intelligence. New York: Suffolk Ltd.

GOODMAN, J 2005: Making sense of humor. Horizons for learning: Lifelong learning. http://www.newhorizons.org/ lifelong/workplace/goodman.htm (accessed 15 September 2006).

GRAVETT, S 2001: Adult learning: Designing and implementing learning events - a dialogic approach. Pretoria: Van Schaik Publishers.

GRAVETT, S \& HENNING E 1998: Teaching as dialogic mediation: a learning-centered view of higher education. South African Journal of Higher Education. 12 (2): 60-68.

HAMMOND, M \& COLLINS, R 1991: Self-directed learning: critical practice. London: Kogan Page.

HAYDEN-MILES, M 2002: Humor in clinical nursing education. Journal of Nursing Education. 41 (9): 420-425.

KELLY, 2005: Teaching with humor and optimism. http://instructordiploma.com/ core/102B/princegeorge/dee.htm. (accessed 4 October 2006).

KLOPPER, H 2000/1: Nursing Education. A reflection. Lynwood Ridge. Amabhuku Publications (Pty) Ltd.

LINCOLN, YS \& GUBA, EG 1985: Naturalistic Inquiry. London: Sage Publications.

LOCKE, EA 2005: Why emotional intelligence is an invalid concept. Journal of Organisational Behavior. 26: 425-431.

McPECK, JE 1981: Critical thinking and Education. Martin Robertson, Oxford.

MOUTON, J 1996: Understanding social research. Pretoria: J.L. van Schaik.
MURPHY,S 1995: The validation event: A critical appraisal? Nurse Education Today, 13: 161-166.

OMERY, A 1983: Phenomenology: a method for nursing research. Advances in Nursing Science. January, 49-63.

PROVINE, R 2000: The science of laughter. Psychologv Today. November/ December 33 (6): 58-62.

SCANLAN, JM \& CHERNOMAS, WM 1997: Developing the reflective teacher. Journal of Advanced Nursing. 25, 11381143.

SOUTH AFIRCAN NURSING COUNCIL, 1978: Nursing Act (Act No. 50 of 1978). Pretoria: Government Printer.

SOUTH AFRICAN NURSING COUNCIL, 1987: Regulations concerning the minimum requirements for registration of the additional qualification in nursing education. Pretoria, Government Notice R, 118, 23 January.

TOROK, SE; McMORRIS, RF \& WENCHI, LIN 2004: Is humor an appreciated teaching tool? Perceptions of professors' teaching styles and use of humor. College Teaching. Washington: Winter, 52 (1): 1420.

THINGUJAM, NS 2004: Current trend and future perspective on emotional intelligence. National Academy of Psvchology, 49 (2/3): 155-166.

ULLOTH, JK 2003: A qualitative view of humor in nursing classrooms. Journal of Nursing Education. March, 42 (3): 125 131.

WLODKOWSKI, RJ 1998: Strategies to enhance adult motivation to learn. In Galbraith, MW (Ed.). Adult learning methods: a guide for effective instruction, $2^{\text {nd }}$ ed. Malabar, FL: Krieger, 91-112.

WOOLFOLK, AE 1990: Educational Psychology. New Jersey: Prentice-Hall. 